\title{
An investigation on the effect of IT management capabilities on role performance of senior IT executives
}

\author{
Hossein Hamidifard $^{\mathrm{a}}$ and Mansoor Aminilari ${ }^{\mathbf{b}^{*}}$
}

${ }^{a}$ MA of EMBA-Strategic Planning, Department of Management, Science and Research branch, Islamic Azad University, Fars, Iran ${ }^{b}$ PhD of DSIS, Department of Computer Engineering, Science and Research branch, Islamic Azad University, Fars, Iran

\section{H R O N I C L E}

Article history:

Received January 4, 2014

Accepted 28 May 2014

Available online

June 22014

Keywords:

Chief information officer

Information technology

management

Role performance

\section{Introduction}

Today's information technology (IT) developments are prevalent across different business enterprise functions and processes. The integration of IT and information system (IS) with business operations has been widely considered as a necessity for building business values, inject new market opportunities, helping process innovation, and shape business vision and strategy to obtain competitive benefits for firms. The necessity for cooperation between IT and business managers involves agreement in such a way to share the risks, responsibilities, and decision right of strategic IT applications. When there is not such opportunity, the distribution of responsibility and accountability between the IT and business units of the firm may fail to acquire, to deploy, and to leverage its IT resources, efficiently. Many firms have aligned technology various applications within their business operations. However, a few of them have successfully integrated their IT and organized these applications with their organizations. Understanding how to align, to synchronize, and to converge

*Corresponding author.

E-mail addresses: Hhamidifard@gmail.com (H.Hamidifard)

C 2014 Growing Science Ltd. All rights reserved. doi: $10.5267 /$ j.msl.2014.6.005 
the spaces of business and IT is thus becoming a critical issue confronting senior IT executives in modern firms. As IT receives more attention in firms, business managers are now anticipated to offer stronger leadership in regard to its deployment of IT in firms. This needs bigger concentration on their ability to learn and to apply IT resources, more effectively. Bassellier et al. (2003) explored the concept of IT competence of business managers as a contributor to their intention to champion IT within their firms. They reported that IT knowledge and IT experience together could explain 34\% of the variance in managers' intentions to champion IT.

Bassellier and Benbasat (2004) aimed at improving the understanding of the concept of business competence of IT professionals as well as exploring the contribution of this competence to the development of partnerships between IT professionals and their business customers. Business competence concentrates on the areas of knowledge, which are not normally specifically IT-related. At a broad level, it includes the organization-specific knowledge and the interpersonal and management knowledge possessed by IT professionals. The results of their survey supported the recommended structure for business competence and indicated that business competence substantially impacts the intentions of IT professionals to develop partnerships with their business clients.

Chun and Mooney (2009) studied how the CIO's job had changed in the past and reported that the CIOs' role had evolved to reflect both the firm's IS infrastructure and strategy. This has yielded into two versions of the role: an executive-level manager concentrated on the firm's strategy and processes, and a technical manager concentrated on minimizing expenses by rationalizing and leveraging the existing IS infrastructure.

\section{The proposed study and methodology}

This paper presents an empirical investigation to study the effects of information management (IT) on senior IT executives. The population of the survey includes all senior IT executives who work for different banks in Iran. The sample size is calculated as follows,

$n=\frac{N \times z_{\alpha / 2}^{2} \times p \times q}{\varepsilon^{2} \times(N-1)+z_{\alpha / 2}^{2} \times p \times q}$,

where $N$ is the population size, $p=1-q$ represents the yes/no categories, $z_{\alpha / 2}$ is CDF of normal distribution and finally $\varepsilon$ is the error term. Since we have $p=0.5, z_{\alpha / 2}=1.96$ and $N=500$, the number of sample size is calculated as $n=118$. For the survey, we consider 62 people are selected from IT managers and 56 people are selected from senior IT executives. The survey uses a questionnaire developed by $\mathrm{Chen}$ and $\mathrm{Wu}$ (2011) and some experts before implementation validated the questionnaire since Cronbach alphas were calculated for two components of the survey as 0.9565 and 0.9531. The proposed study of this paper considers the following three hypotheses,

$\mathrm{H}_{1}$. CIOs' superior IT competency will positively associate with IT management activity effectiveness.

$\mathrm{H}_{2}$. CIOs' superior management competency will positively associate with IT management activity effectiveness.

$\mathrm{H}_{3}$. A higher level of IT management activity effectiveness will positively associate with CIO role performance.

Before applying any statistical test, the study needs to make sure about the normality of different components, which has been accomplished by applying Kolmogorov-Smirnov test. Table 1 shows details of our survey. 
Table 1

The summary of Kolmogorov-Smirnov test

\begin{tabular}{|c|c|c|c|c|c|c|}
\hline & Attribute & Number & Mean & Standard deviation & KS & P-value \\
\hline \multirow{10}{*}{ Senior IT Executives(CIOs) } & IT infrastructure & 62 & 22.13 & 5.1 & 1.128 & 0.157 \\
\hline & Business development applications & 62 & 13 & 3.97 & 0.784 & 0.571 \\
\hline & Integration "business" with Technology & 62 & 18.03 & 4.57 & 1.051 & 0.22 \\
\hline & Knowledge of a range of business & 62 & 17.77 & 4.54 & 0.665 & 0.768 \\
\hline & Knowledge or skills, "Interpersonal Communication" & 62 & 17.32 & 4.32 & 0.976 & 0.296 \\
\hline & Business management techniques & 62 & 18.71 & 5.03 & 1.052 & 0.219 \\
\hline & Governance and Organization & 62 & 23.45 & 7.27 & 0.855 & 0.458 \\
\hline & Investment Management - IT Field & 62 & 18.17 & 5.2 & 0.824 & 0.505 \\
\hline & Strategy and Planning & 62 & 20.98 & 5.74 & 1.204 & 0.11 \\
\hline & Strategic architecture & 62 & 23.05 & 7.1 & 1.097 & 0.18 \\
\hline \multirow{14}{*}{$\begin{array}{l}\text { Top Management } \\
\text { Team(TMT) } \\
\text { n-IT Senior Executives }\end{array}$} & IT infrastructure & 62 & 19.11 & 6.61 & 0.945 & 0.334 \\
\hline & Business development applications & 62 & 13.32 & 4.06 & 0.884 & 0.415 \\
\hline & Integration "business" with Technology & 62 & 17.94 & 4.25 & 0.867 & 0.439 \\
\hline & Knowledge of a range of business & 62 & 16.03 & 5.66 & 0.919 & 0.367 \\
\hline & Knowledge or skills, "Interpersonal Communication" & 62 & 16.06 & 5.56 & 0.987 & 0.284 \\
\hline & Business management techniques & 62 & 17.61 & 4.89 & 0.891 & 0.405 \\
\hline & Business ideas & 62 & 14.61 & 3.18 & 0.82 & 0.512 \\
\hline & Thoughtful business system & 62 & 11.56 & 2.07 & 1.354 & 0.051 \\
\hline & Shaping the Values of the organization & 62 & 15.03 & 3.32 & 1.114 & 0.167 \\
\hline & Entrepreneur & 62 & 11.82 & 2.29 & 1.544 & 0.067 \\
\hline & Creating infrastructure & 62 & 14.08 & 3.52 & 0.944 & 0.335 \\
\hline & The Designer & 62 & 11.37 & 2.38 & 0.996 & 0.274 \\
\hline & Building relationship & 62 & 12.97 & 3.37 & 1.113 & 0.168 \\
\hline & Informed and knowledgeable buyer & 62 & 14.87 & 3.84 & 0.815 & 0.52 \\
\hline
\end{tabular}

As we can observe from the results of Table 1, all components of the survey are normally distributed. Investigating the correlation ratios has indicated a positive and meaningful relationship between different components of the questionnaire.

\section{The results}

In this section, we present details of the results of our survey. Fig. 1 and Fig. 2 show details of standard coefficients and t-student values, respectively.

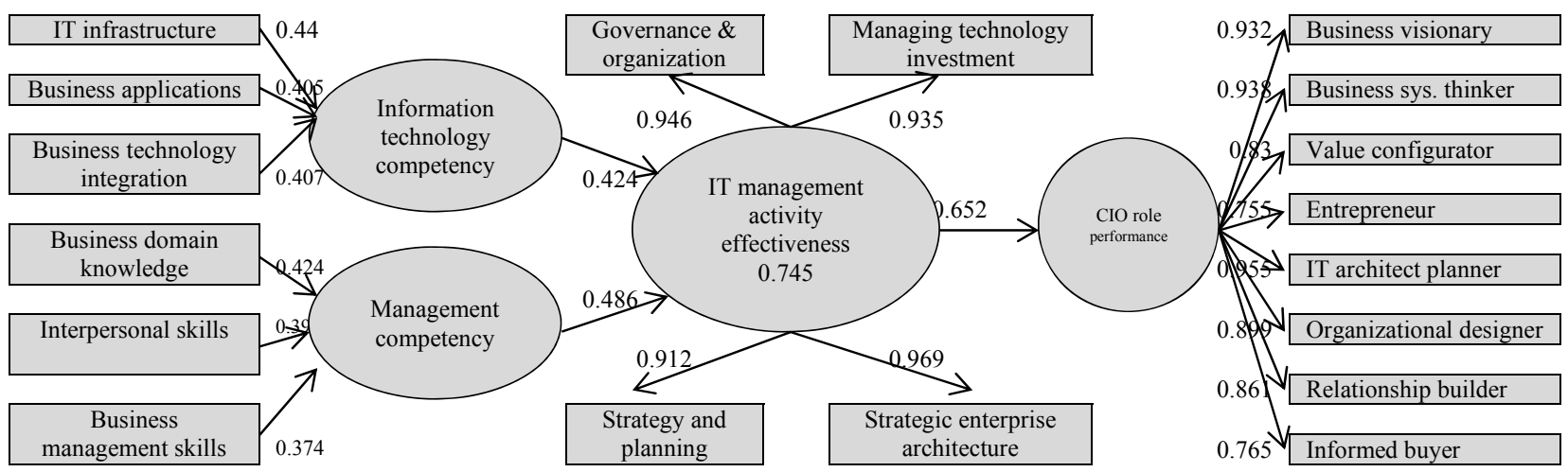

Fig. 1. The results of the standard coefficients for PLS

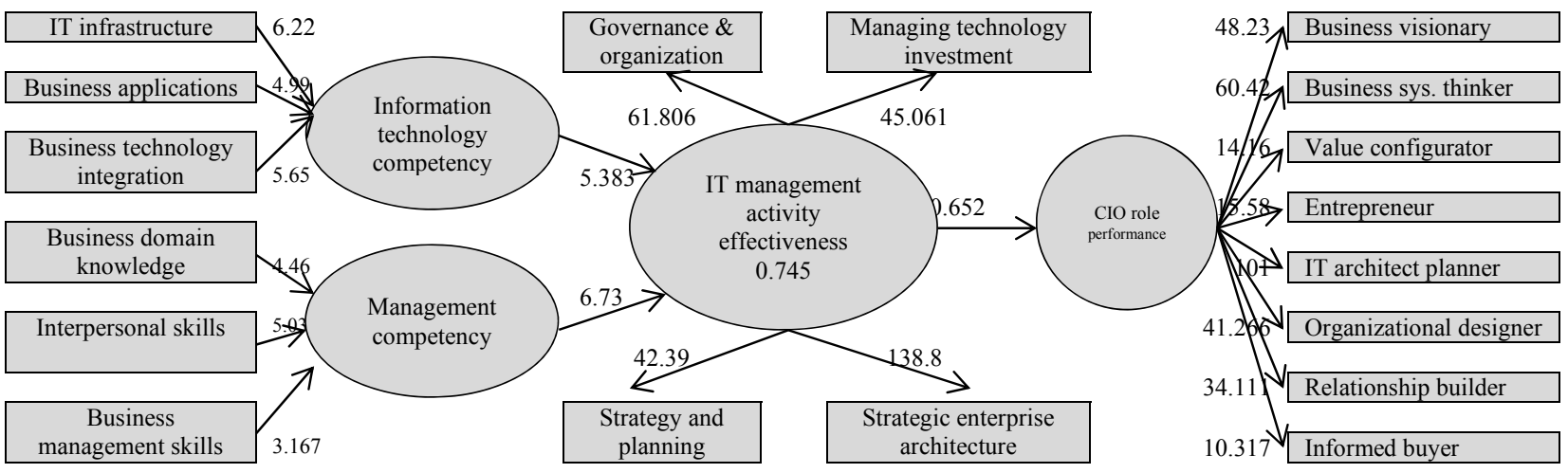

Fig. 2. The results of t-student values for PLS 
As we can observe from the results of Fig. 2, all student values are meaningful when the level of significance is one percent. Table 2 summarizes the results of our investigations.

\section{Table 2}

The summary of examining three hypotheses

\begin{tabular}{llcccc}
\hline Hypothesis & & $\beta$ & t-value & Sig. & Result \\
\hline $\begin{array}{l}\text { CIOs' superior IT competency will positively associate with IT } \\
\text { management activity effectiveness. }\end{array}$ & 0.424 & 5.383 & $\mathrm{P}<0.01$ & Confirmed \\
$\begin{array}{l}\mathrm{H}_{2} \text {. CIOs' superior management competency will positively associate with } \\
\text { IT management activity effectiveness. }\end{array}$ & 0.485 & 6.730 & $\mathrm{P}<0.01$ & Confirmed \\
$\begin{array}{l}\text { H3. A higher level of IT management activity effectiveness will positively } \\
\text { associate with CIO role performance. }\end{array}$ & 0.652 & 7.981 & $\mathrm{P}<0.01$ & Confirmed \\
\hline
\end{tabular}

\section{Conclusion}

In this paper, we have proposed a framework of IT management capability and tested its effects on $\mathrm{CIO}$ role performance in a case study of banking industry. By investigating the performance of CIO roles and the importance of IT management capability, the predictive validities of the major constructs of IT management capability on CIOs' levels of role performance were evaluated. The findings of our survey have added to the body of knowledge by evaluating the human-resource based capability of IT management needed by CIOs and the effects of them on the CIO's role performance and on the effectiveness of IT management activities. The results of this survey are consistent with findings of Chen and $\mathrm{Wu}$ (2011), Reich and Benbasat (2000), Smaltz et al. (2006) and Sambamurthy et al. (2003).

\section{Acknowledgement}

The authors would like to thank the anonymous referees for constructive comments on earlier version of this paper.

\section{References}

Bassellier, G., Benbasat, I., \& Reich, B. H. (2003). The influence of business managers' IT competence on championing IT. Information Systems Research,14(4), 317-336.

Bassellier, G., \& Benbasat, I. (2004). Business competence of information technology professionals: Conceptual development and influence on IT-business partnerships. MIS Quarterly, 28(4), 673694.

Chen, Y. C., \& Wu, J. H. (2011). IT management capability and its impact on the performance of a CIO. Information \& Management, 48(4), 145-156.

Chun, M., \& Mooney, J. (2009). CIO roles and responsibilities: Twenty-five years of evolution and change. Information \& Management, 46(6), 323-334.

Reich, B. H., \& Benbasat, I. (2000). Factors that influence the social dimension of alignment between business and information technology objectives. MIS Quarterly, 24(1), 81-113.

Sambamurthy, V., Bharadwaj, A., \& Grover, V. (2003). Shaping agility through digital options: Reconceptualizing the role of information technology in contemporary firms. MIS quarterly, 237263.

Smaltz, D. H., Sambamurthy, V., \& Agarwal, R. (2006). The antecedents of CIO role effectiveness in organizations: An empirical study in the healthcare sector. Engineering Management, IEEE Transactions on, 53(2), 207-222. 